\title{
Complete remission of advanced hepatocellular carcinoma following transient chemoembolization and portal vein ligation
}

Yuki Koga ${ }^{1,2}$, Toru Beppu ${ }^{1,2}$, Katsunori Imai ${ }^{2}$, Kunitaka Kuramoto ${ }^{1,2}$, Tatsunori Miyata², Yuki Kitano², Shigeki Nakagawa², Hirohisa Okabe ${ }^{2}$, Kazutoshi Okabe ${ }^{2}$, Yo-ichi Yamashita ${ }^{2}$, Akira Chikamoto ${ }^{2}$ and Hideo Baba ${ }^{2 *}$ (D)

\begin{abstract}
Background: Macroscopic diffuse-type hepatocellular carcinoma with concomitant major portal vein tumor thrombus (PVTT) and peritoneal dissemination indicates poor prognosis. Additionally, triple-positive tumor marker status is a predictor of poor outcome even after hepatectomy. Sorafenib is recommended in such patients, but it has limited therapeutic effectiveness.
\end{abstract}

Case presentation: A 54-year-old man was diagnosed with a liver abscess that was treated by puncture and drainage at a regional hospital. However, the diagnosis was subsequently changed to hepatocellular carcinoma with macroscopic portal vein tumor thrombus, based on the results obtained for the triple-positive tumor markers (alpha-fetoprotein, 45,928 ng/ml; protein induced by vitamin K absence or antagonist-II, 125,350 mAU/ml; and alpha-fetoprotein-L3, 38.3\%). As the patient's liver functional reserve was not adequate for curative resection, chemoembolization was performed with a hepatic arterial infusion of cisplatin (50 mg) and 5-FU (1000 mg), followed by mild embolization with cisplatin $(50 \mathrm{mg}$ ) suspended in lipiodol $(5 \mathrm{ml})$ and starch microspheres (300 mg) containing mitomycin C (4 mg). As the thrombus had progressed to the bifurcation of the right and left portal veins, the right vein was surgically ligated. Three peritoneal nodules could be identified and were removed. Three additional rounds of hepatic arterial chemotherapy/chemoembolization were performed after the initial surgery. At the 2-year evaluation, all tumor markers were observed to have normalized and diagnostic imaging showed complete remission.

Conclusions: Complete remission of hepatocellular carcinoma with macroscopic portal vein tumor thrombus and peritoneal dissemination was obtained with a treatment regimen that involved four rounds of hepatic arterial infusion chemotherapy and transient chemoembolization, portal vein ligation, and the removal of peritoneal dissemination. This regimen can be recommended for patients with advanced hemiliver lesions who cannot undergo curative resection.

Keywords: Hepatocellular carcinoma, Portal vein tumor thrombus, Peritoneal dissemination, Complete remission, Chemoembolization, Portal vein ligation

\footnotetext{
* Correspondence: hdobaba@kumamoto-u.ac.jp

${ }^{2}$ Department of Gastroenterological Surgery, Graduate School of Life

Sciences Kumamoto University, 1-1-1 Honjo, Chuo-ku, Kumamoto 860-8556,

Japan

Full list of author information is available at the end of the article
} 


\section{Background}

Macroscopic diffuse-type hepatocellular carcinoma (HCC) with concomitant major portal vein tumor thrombus (PVTT) and peritoneal dissemination suggests poor prognosis in the patients with HCC [1-4]. A triple-positive tumor marker status also predicts a poor outcome [5-7], and even though patients with advanced HCC are often treated with sorafenib, tumor control and survival rates remain unsatisfactory $[8,9]$. Chemoembolization is an option for treating advanced HCC; however, it is contraindicated in patients with a main to first portal vein branch [10]. In such patients, hepatic arterial infusion chemotherapy (HAIC), followed by transient chemoembolization using temporary embolic materials, is an alternative treatment option $[11,12]$. Portal vein embolization (PVE) or portal vein ligation (PVL) can broaden the indications for liver resection in patients with $\mathrm{HCC}$ and major PVTT [13]. Even in unresectable HCC with macroscopic PVTT, PVE can avoid metastasis of the non-embolized liver and can improve overall survival rate [14]. We report a case of complete remission of a diffuse-type HCC with PVTT after four rounds of transient chemoembolization combined with surgical PVL and extirpation of peritoneal dissemination.

\section{Case presentation}

A 54-year-old man with a history of diabetes mellitus and hypertension was admitted to a regional hospital because of high fever and right hypochondriac pain. Hepatitis $B$ virus surface antigen and hepatitis $C$ virus antibody were both found to be negative, but he showed evidence of an excessive inflammatory reaction. A diagnosis of liver abscess was carried out that was managed by immediately performing a percutaneous puncture with drainage. Laboratory evaluation (Table 1) found poor liver function and very high levels of alphafetoprotein (AFP, 45,928 ng/ml; normal, $\leq 20 \mathrm{ng} / \mathrm{ml}$ ),
Table 1 Laboratory values on admission

\begin{tabular}{lcllll}
\hline T-protein & 7.2 & $\mathrm{~g} / \mathrm{dl}$ & AFP & 45,928 & $\mathrm{ng} / \mathrm{ml}$ \\
Albumin & 1.9 & $\mathrm{~g} / \mathrm{dl}$ & PIVKA-Il & 125,350 & $\mathrm{AU} / \mathrm{ml}$ \\
T-bilirubin & 1.2 & $\mathrm{mg} / \mathrm{dl}$ & AFP-L3 & 38.3 & $\%$ \\
D-bilirubin & 0.6 & $\mathrm{mg} / \mathrm{dl}$ & & & \\
ALT & 30 & $\mathrm{U} / \mathrm{L}$ & HBs-Ag & $(-)$ & \\
AST & 136 & $\mathrm{U} / \mathrm{L}$ & HBs-Ab & $(-)$ & \\
LDH & 468 & $\mathrm{U} / \mathrm{L}$ & HBc-Ab & $(-)$ & \\
ALP & 992 & $\mathrm{U} / \mathrm{L}$ & HCV-Ab & $(-)$ & \\
Y-GTP & 524 & $\mathrm{U} / \mathrm{L}$ & & & \\
Cholinesterase & 79 & $\mathrm{U} / \mathrm{L}$ & White blood cell & 12.38 & $\times 10^{3} / \mu \mathrm{L}$ \\
& & & Neutrophils & 86.2 & $\%$ \\
& & & Red blood cell & 3.55 & $\times 10^{6} / \mu \mathrm{L}$ \\
BUN & 10.1 & $\mathrm{mg} / \mathrm{dl}$ & Hemoglobin & 10.1 & $\mathrm{~g} / \mathrm{dl}$ \\
Creatinine & 0.41 & $\mathrm{mg} / \mathrm{dl}$ & Platelet & 343 & $\times 10^{3} / \mu \mathrm{L}$ \\
FBS & 106 & $\mathrm{mg} / \mathrm{dl}$ & CRP & 25.01 & $\mathrm{mg} / \mathrm{dl}$ \\
Hb A1c & 6.3 & $\%$ & PT activity & 54.2 & $\%$ \\
\hline ALT & & & ICG R15 & 32.6 & $\%$ \\
\hline
\end{tabular}

ALT alanine transaminase, AST aspartate aminotransferase, $\gamma$-GTP, $\gamma$-glutamyl transpeptidase, $L D H$ lactate dehydrogenase, $A L P$ alkaline phosphatase, $B U N$ blood urea nitrogen, FBS fasting blood glucose, $\mathrm{Hb}$ hemoglobin, AFP alphafetoprotein, PIVKA-I/ protein induced by vitamin $\mathrm{K}$ absence or antagonist-II, $H B s-A g$ and $H B s-A b$ hepatitis $B$ virus surface antigen and antibody, $H B C-A b$ hepatitis $B$ virus core antibody, HCV-Ab hepatitis $C$ virus antibody, $C R P C$ reactive protein, $P T$ prothrombin time, ICGR15 indocyanine green retention rate at $15 \mathrm{~min}$

protein induced by vitamin $\mathrm{K}$ absence or antagonist-II (PIVKA-II, 125,350 mAU/ml; normal, $\leq 40 \mathrm{mAU} / \mathrm{ml}$ ), and AFP-L3 (38.3\%, normal, $\leq 10 \%)$. The patient was diagnosed with HCC and with the triple-positive tumor marker status indicating highly malignant disease $[5,6]$. The patient was also found to have a portal vein tumor thrombosis in the right posterior branch of the portal vein (Fig. 1). Although a right hepatectomy was indicated for curative resection, residual liver function of
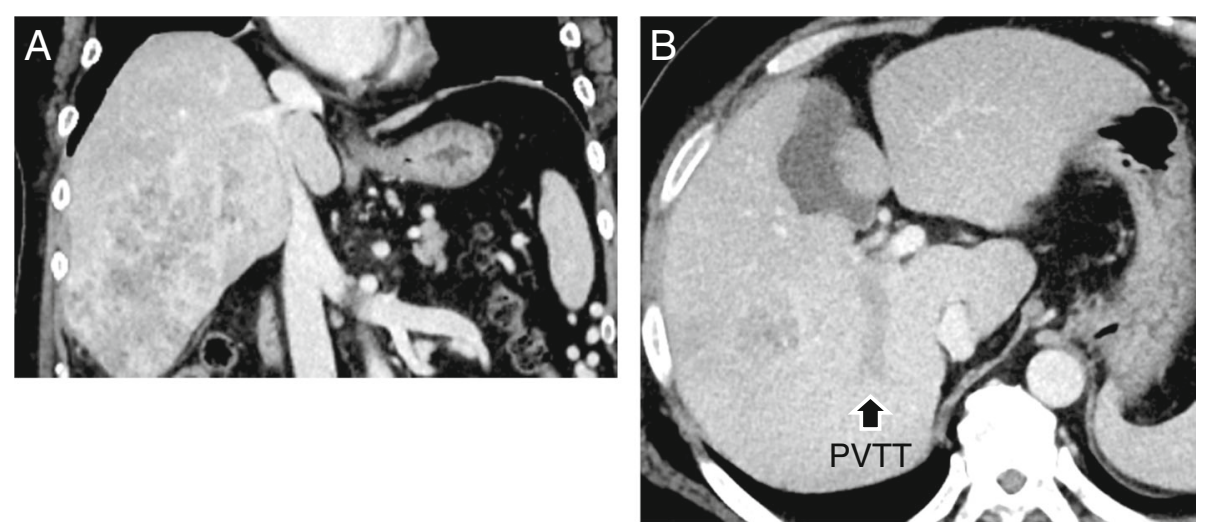

Fig. 1 Dynamic CT scan on admission to our hospital. a Coronal view (portal phase). b Axial view (portal phase). Dynamic CT showed a large diffusetype HCC with a PVTT in the right posterior branch of the portal vein (arrow) 
the remnant volume was estimated to be insufficient $[15,16]$.

The patient was initially treated with chemoembolization (Table 2) using a HAIC of cisplatin $(50 \mathrm{mg} /$ $100 \mathrm{ml} / 10 \mathrm{~min})$ and 5 -FU $(1000 \mathrm{mg} / 100 \mathrm{ml} / 10 \mathrm{~min})$, followed by cisplatin $(50 \mathrm{mg}$ ) suspended in lipiodol $(5 \mathrm{ml})$ and starch microspheres $(300 \mathrm{mg})$ containing mitomycin C (4 mg) [11, 12]. After the first round of chemoembolization, examination showed incomplete lipiodol accumulation within the tumor. Additionally, as the PVTT progressed to the right main portal vein, surgical PVL was performed to avoid involvement of the left portal vein. Three disseminated peritoneally nodules were also removed. Three additional rounds of transient chemoembolization were performed after the initial surgical procedure.

At the time of the fourth chemoembolization, the tumors responded to the treatment and markedly reduced in size without enhancement (Fig. 2). Further, no new tumors were found in the liver, and the tumor markers returned to their normal levels (Fig. 3). A suspicious lesion $(2 \mathrm{~cm}$ in diameter) recurred at 15 months after the initial treatment, which was treated with percutaneous radiofrequency ablation. The patient is alive at 2-year post-procedure and shows complete remission, as defined by the modified response evaluation criteria in solid tumor criteria.

\section{Discussion}

This patient achieved complete remission after chemoembolization, surgical PVL, and extirpation of peritoneally disseminated nodules. The case was complicated by the poor prognostic factors, including the macroscopic diffuse-type classification, a macroscopic PVTT, the peritoneal dissemination, and triple-positive tumor marker status [1-6]. A tumor biopsy was not performed, but the presence of a poorly differentiated HCC was strongly suggested by the tumor marker status and diagnostic imaging [5-7].

In patients with $\mathrm{HCC}$ and macroscopic PVTT, multidisciplinary treatment, including liver resection, provides an excellent prognosis [17]. Moreover, a recent nationwide survey in Japan indicated that liver resection was more effective than non-surgical treatment in cases with a PVTT that is limited to the first- or second-order branches [18]. Multiple measurements of the liver function and functional liver volume after PVL $[15,16,19]$ in our patient indicated that liver resection was not a viable option. For such HCC patients, other treatment options such as HAIC with chemoembolization and sorafenib also result in poor median survival times of $3.5-10.2$ and 8.18.9 months, respectively $[17,20]$. However, right portal vein occlusion can prevent both progression of the right PVTT into the left or main portal vein and intrahepatic metastasis into the left liver [13, 14, 21], and it may also enhance the effectiveness of HAIC because capsular invasion and satellite nodules could be supplied by the portal vein with hepatic artery [14, 22]. While formulating the treatment strategy, we also considered the fact that PVE is not indicated in patients with a PVTT that is in close proximity to the bifurcation.

Peritoneal dissemination of HCC can occur after tumor rupture or due to therapeutic interventions. The standard treatment for dissemination of $\mathrm{HCC}$ would be systemic chemotherapy, and if dissemination is localized to abdominal cavity or abdominal wall, then the surgical removal for dissemination of HCC might be a challenging option [23, 24]. In this patient, iatrogenic seeding may have occurred by tumor puncture when drainage was started. However, the spread was limited, and all lesions could be isolated and surgically removed.

Our patient was treated by HAIC followed by transient chemoembolization. Cisplatin and 5-FU are effective for $\mathrm{HCC}$, evidently in intra-arterial infusion $[25,26]$. In fact, some patients with advanced HCC and PVTT have reportedly shown complete clinical remission or pathological response after this regimen [27-29]. Cisplatin modulates 5-FU activity, and the two drugs seem to have a synergistic effect. Further, as cisplatin infused via the hepatic artery is not trapped in the liver parenchyma, it would also be effective as systemic chemotherapy. Essentially, cisplatin suspended in lipiodol is a highly effective embolic material that is also used in HCC treatment [26, 30, 31]. Mitomycin-C and degradable starch microspheres provide temporary occlusion, which may also increase drug concentration [11].

Table 2 Hepatic arterial infusion and chemoembolization treatment regimen

\begin{tabular}{lllll}
\hline & First & Second & Third & Fourth \\
\hline Cisplatin solution & $50 \mathrm{mg}$ & $50 \mathrm{mg}$ & $50 \mathrm{mg}$ & $80 \mathrm{mg}$ \\
5-FU solution & $1000 \mathrm{mg}$ & $1000 \mathrm{mg}$ & $1000 \mathrm{mg}$ & $1000 \mathrm{mg}$ \\
Cisplatin/lipiodol suspension & $50 \mathrm{mg} / 5.0 \mathrm{ml}$ & $45 \mathrm{mg} / 4.5 \mathrm{ml}$ & $30 \mathrm{mg} / 3.0 \mathrm{ml}$ & - \\
Farmorubicin/lipiodol emulsion & - & - & - & $20 \mathrm{mg} / 2.0 \mathrm{ml}$ \\
MMC/Spherex & $4 \mathrm{mg} / 300 \mathrm{mg}$ & $4 \mathrm{mg} / 300 \mathrm{mg}$ & $4 \mathrm{mg} / 300 \mathrm{mg}$ & $4 \mathrm{mg} / 180 \mathrm{mg}$ \\
\hline
\end{tabular}

5-FU 5-fluorouracil, MMC mytomycin C 

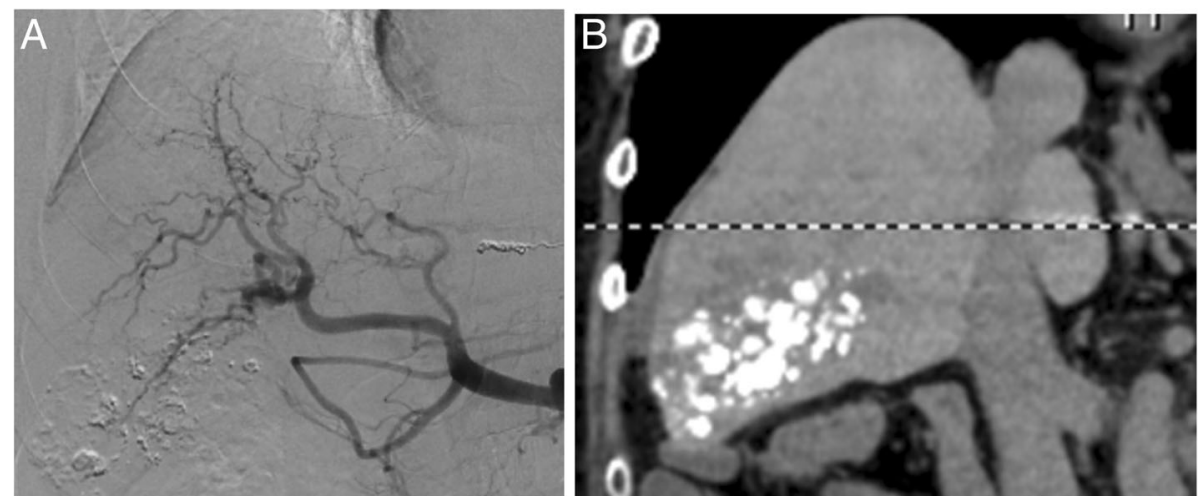

Fig. 2 Diagnostic images at the fourth chemoembolization procedure. a Digital subtraction angiography. b Plain CT after chemoembolization. The main tumor is markedly diminished with no enhancement, and lipiodol showed spotty but strong accumulation

Sorafenib is effective in HCC patients with macroscopic vascular invasions, extrahepatic spread, or both, but a recent trial has reported a response rate of $2 \%$ and a median survival time of only 10.7 months [8]. However, a few cases of complete remission after sorafenib therapy have been reported [32, 33]. In our patient, dynamic imaging detected no viable $\mathrm{HCC}$ and persisting normalization of the three tumor markers. Previous reports suggest that HAIC with a cisplatinlipiodol suspension combined with 5-FU can lead to better response rates and overall survival rates (without extrahepatic metastasis) compared to only sorafenib in patients with advanced HCC and PVTT [26]. Thus, it would be possible to administer additional chemoembolization or radiofrequency ablation for intrahepatic recurrence and sorafenib therapy for extrahepatic metastasis. It has similarly been reported that sorafenib is effective in patients with HCC refractory to chemoembolization [34] and that sorafenib and HAIC with cisplatin may have synergistic effects [35].

The maintenance of liver function is the key to achieving longer survival in advanced HCC patients, and it is known that effective treatment for advanced HCC can improve liver function [36]. Further, it has been reported that a Child-Pugh score of $\leq 7$ shows a better response to HAIC with better prognosis compared with Child-Pugh score of 8 or 9 [37]. However, our patient had a Child-Pugh score of 8 at admission, which improved to 6 after multidisciplinary

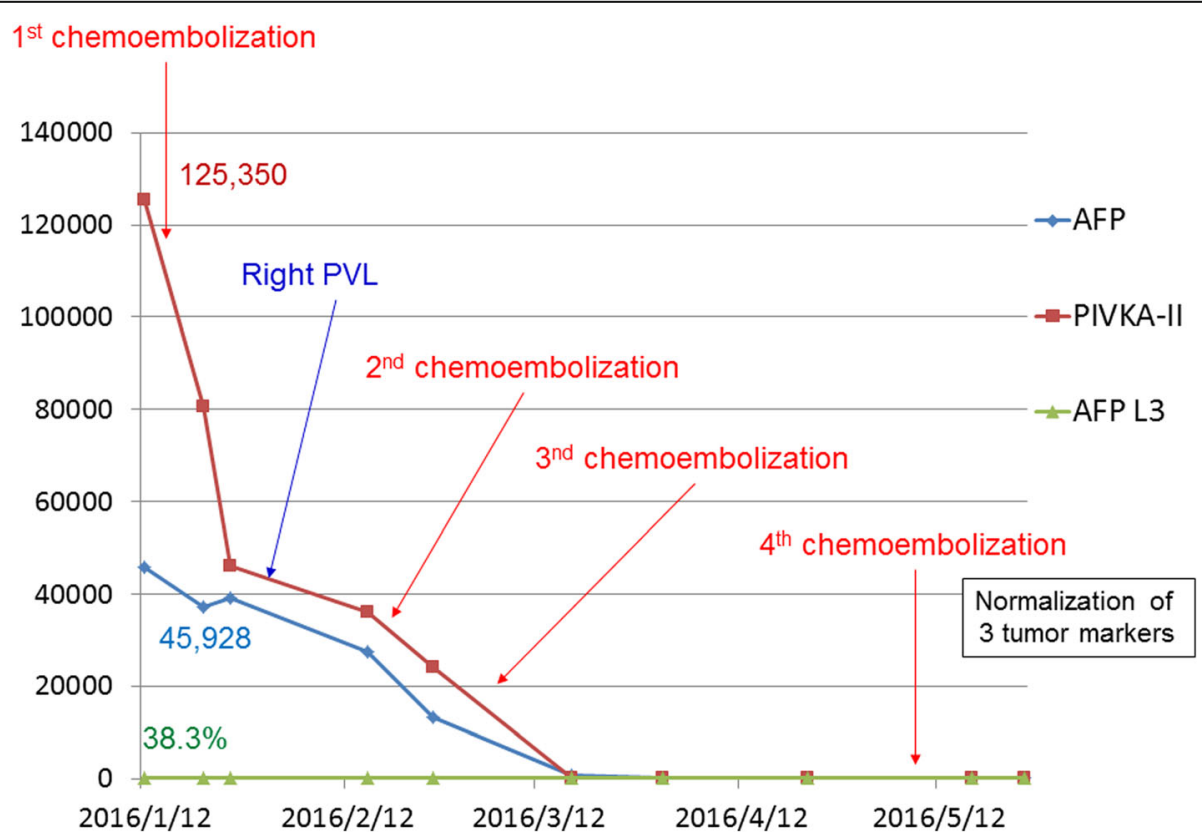

Fig. 3 Treatment course and changes in tumor markers. Tumor markers were abnormally high before the first chemoembolization, but they remained within the normal range for 18 months after the fourth chemoembolization procedure 
treatment, indicating that the treatment regimen was effective.

\section{Conclusions}

A treatment consisting of chemoembolization and surgical intervention, including PVL, may allow complete remission in patients with advanced hemiliver lesions, PVTT, and/or localized peritoneal dissemination.

\section{Abbreviations}

AFP: Alpha-fetoprotein; ALP: Alkaline phosphatase; ALT: Alanine transaminase; AST: Aspartate aminotransferase; BUN: Blood urea nitrogen; CRP: C-reactive protein; CT: Computed tomography; FBS: Fasting blood glucose; Hb: Hemoglobin; $\mathrm{HBC}-\mathrm{Ab}$ : Hepatitis B virus core antibody; $\mathrm{HBs}-\mathrm{Ag}$ and $\mathrm{HBs}-\mathrm{Ab}$ : Hepatitis B virus surface antigen and antibody; HCC: Hepatocellular carcinoma; HCV-Ab: Hepatitis C virus antibody; Y-GTP: $y$-Glutamyl transpeptidase; ICGR15: Indocyanine green retention rate at $15 \mathrm{~min}$; LDH: Lactate dehydrogenase; PIVKA-II: Protein induced by vitamin K absence or antagonist-II; PT: Prothrombin time; PVTT: Portal vein tumor thrombus; PVL: Portal vein ligation; PVE: Portal vein embolization; RECIST: Response evaluation criteria in solid tumors

\section{Authors' contributions}

YK and TB mainly participated in the conception, design, and analysis of this case report and drafted the manuscript. $\mathrm{KI}, \mathrm{KK}, \mathrm{TM}, \mathrm{YK}, \mathrm{SN}, \mathrm{HO}, \mathrm{KO}, \mathrm{YY}$, and $A C$ conceived of the study and participated in its design and coordination and helped to draft the manuscript. TB and $\mathrm{HB}$ were responsible for this paper. All authors read and approved the final manuscript.

\section{Consent for publication}

Written informed consent was taken from the patient for publication of this case report and all accompanying imaging.

\section{Competing interests}

The authors declare that they have no competing interests.

\section{Publisher's Note}

Springer Nature remains neutral with regard to jurisdictional claims in published maps and institutional affiliations.

\section{Author details}

'Department of Surgery, Yamaga City Medical Center, Kumamoto, Japan. 2Department of Gastroenterological Surgery, Graduate School of Life Sciences Kumamoto University, 1-1-1 Honjo, Chuo-ku, Kumamoto 860-8556, Japan

Received: 12 October 2017 Accepted: 16 August 2018

Published online: 29 August 2018

\section{References}

1. Ikai l, Arii S, Kojiro M, et al. Reevaluation of prognostic factors for survival after liver resection in patients with hepatocellular carcinoma in a Japanese nationwide survey. Cancer. 2004;101(4):796-802.

2. Nara S, Shimada K, Sakamoto Y, et al. Prognostic impact of marginal resection for patients with solitary hepatocellular carcinoma: evidence from 570 hepatectomies. Surgery. 2012;151(4):526-36.

3. Sakon M, Monden M, Umeshita $\mathrm{K}$, et al. The prognostic significance of macroscopic growth pattern of hepatocellular carcinoma. Int Surg. 1994; 79(1):38-42.

4. The Cancer of the Liver Italian Program Investigators. A new prognostic system for hepatocellular carcinoma: a retrospective study of 435 patients: the Cancer of the Liver Italian Program (CLIP) investigators. Hepatology. 1998;28:751-5.

5. Kiriyama S, Uchiyama K, Ueno M, et al. Triple positive tumor markers for hepatocellular carcinoma are useful predictors of poor survival. Ann Surg. 2011;254(6):984-91.

6. Nakagawa S, Beppu T, Okabe H, et al. Triple positive tumor markers predict recurrence and survival in early stage hepatocellular carcinoma. Hepatol Res. 2014;44(9):964-74.
7. Nitta H, Nakagawa S, Kaida T, et al. Pre-treatment double- or triple-positive tumor markers are predictive of a poor outcome for patients undergoing radiofrequency ablation for hepatocellular carcinoma. Surg Today. 2017; 47(3):375-84.

8. Llovet JM, Ricci S, Mazzaferro V, et al. SHARP Investigators Study Group. Sorafenib in advanced hepatocellular carcinoma. N Engl J Med 2008;359:378-390.

9. Cheng AL, Kang YK, Chen Z, et al. Efficacy and safety of sorafenib in patients in the Asia-Pacific region with advanced hepatocellular carcinoma: a phase III randomised, double-blind, placebo-controlled trial. Lancet Oncol. 2009;10:25-34.

10. Beppu T, Ohara C, Yamaguchi Y, et al. A new approach to chemoembolization for unresectable hepatocellular carcinoma using aclarubicin microspheres in combination with cisplatin suspended in iodized oil. Cancer. 1991;68:2555-60.

11. Ishida K, Hirooka M, Hiraoka A, et al. Treatment of hepatocellular carcinoma using arterial chemoembolization with degradable starch microspheres and continuous arterial infusion of 5-fluorouracil. Jpn J Clin Oncol. 2008;38:596-603.

12. Nitta H, Beppu T, Imai $K$, et al. Adjuvant hepatic arterial infusion chemotherapy after hepatic resection of hepatocellular carcinoma with macroscopic vascular invasion. World J Surg. 2013;37(5):1034-42.

13. Beppu T, Okabe H, Okuda K, et al. Portal vein embolization followed by right-side hemihepatectomy for hepatocellular carcinoma patients: a Japanese multi-institutional study. J Am Coll Surg. 2016;222(6):1138-48.

14. Okabe K, Beppu T, Masuda T, et al. Portal vein embolization can prevent intrahepatic metastases to non-embolized liver. Hepato-Gastroenterology. 2012;59(114):538-41.

15. Okabe H, Beppu T, Hayashi H, et al. Rank classification based on the combination of indocyanine green retention rate at $15 \mathrm{~min}$ and $(99 \mathrm{~m}) \mathrm{Tc}$ DTPA-galactosyl human serum albumin scintigraphy predicts the safety of hepatic resection. Nucl Med Commun. 2014;35(5):478-83.

16. Hayashi H, Beppu T, Okabe $H$, et al. Functional assessment versus conventional volumetric assessment in the prediction of operative outcomes after major hepatectomy. Surgery. 2015;157(1):20-6.

17. Katagiri S, Yamamoto M. Multidisciplinary treatments for hepatocellular carcinoma with major portal vein tumor thrombus. Surg Today. 2014:44: 219-26.

18. Kokudo T, Hasegawa K, Matsuyama Y, et al. Liver Cancer Study Group of Japan. Survival benefit of liver resection for hepatocellular carcinoma associated with portal vein invasion. J Hepatol 2016:65(5):938-943.

19. Beppu T, Hayashi $H$, Okabe $H$, et al. Liver functional volumetry for portal vein embolization using a newly developed 99 mTc-galactosyl human serum albumin scintigraphy SPECT-computed tomography fusion system. J Gastroenterol. 2011:46(7):938-43.

20. Bruix J, Raoul JL, Sherman M, et al. Efficacy and safety of sorafenib in patients with advanced hepatocellular carcinoma: subanalyses of a phase III trial. J Hepatol. 2012;57(4):821-9.

21. Pandanaboyana $S$, Bell $R$, Hidalgo $E$, et al. A systematic review and meta-analysis of portal vein ligation versus portal vein embolization for elective liver resection. Surgery. 2015;157(4):690-8

22. Honda $\mathrm{H}$, Tajima $\mathrm{T}$, Taguchi $\mathrm{K}$, et al. A recent developments in imaging diagnostics for HCC: CT arteriography and CT arterioportography evaluation of vascular changes in premalignant and malignant hepatic nodules. J Hepato-Biliary-Pancreat Surg. 2000;7(3):245-51.

23. Yeh CN, Chen MF, Jeng LB. Resection of peritoneal implantation from hepatocellular carcinoma. Ann Surg Oncol. 2002;9:863-8.

24. Yamamoto N, Okano K, Kushida $Y$, et al. Clinicopathology of recurrent hepatocellular carcinomas after radiofrequency ablation treated with salvage surgery. Hepatol Res. 2014;44(11):1062-71.

25. Hoshida Y, Moriyama M, Otsuka M, et al. Identification of genes associated with sensitivity to 5 -fluorouracil and cisplatin in hepatoma cells. J Gastroenterol. 2002;37(Suppl 14):92-5.

26. Furukawa S. In vitro chemosensitivity of hepatocellular carcinoma for hepatic arterial infusion chemotherapy using the MTT assay with the combinations of antitumor drugs. Kurume Med J. 2004;51:25-33.

27. Obi S, Yoshida H, Toune $\mathrm{R}$, et al. Combination therapy of intraarterial 5fluorouracil and systemic interferonalpha for advanced hepatocellular carcinoma with portal venous invasion. Cancer. 2006:106(9):1990-7.

28. Nakano M, Niizeki T, Nagamatsu H, et al. Clinical effects and safety of intraarterial infusion therapy of cisplatin suspension in lipiodol combined with 5 fluorouracil versus sorafenib, for advanced hepatocellular carcinoma with macroscopic vascular invasion without extra-hepatic spread: a prospective cohort study. Mol Clin Oncol. 2017;7(6):1013-20. 
29. Kim YG, Eun JR, Kim TN, et al. Pathological complete remission of advanced hepatocellular carcinoma with main portal vein tumor thrombosis by hepatic arterial infusion chemotherapy. Gut Liver. 2010;4(2):266-9.

30. Beppu T, Ohara C, Yamaguchi Y, et al. A new approach to chemoembolization for unresectable hepatocellular carcinoma using aclarubicin microspheres in combination with cisplatin suspended in iodized oil. Cancer. 1991;68(12):2555-60,

31. Nagamatsu $H$, Sumie $S$, Niizeki T, et al. Hepatic arterial infusion chemoembolization therapy for advanced hepatocellular carcinoma: multicenter phase II study. Cancer Chemother Pharmacol. 2016;77(2): 243-50.

32. Kudo M, Ueshima K. Positioning of a molecular-targeted agent, sorafenib, in the treatment algorithm for hepatocellular carcinoma and implication of many complete remission cases in Japan. Oncology. 2010;78(Suppl 1):154-66.

33. Curtit E, Thiery-Vuillemin A, Nguyen T, et al. Complete histologic response induced by sorafenib in advanced hepatocellular carcinoma: a case report. J Clin Oncol. 2011;29:e330-2.

34. Ikeda M, Shimizu S, Sato T, et al. Sorafenib plus hepatic arterial infusion chemotherapy with cisplatin versus sorafenib for advanced hepatocellular carcinoma: randomized phase II trial. Ann Oncol. 2016;27(11):2090-6.

35. Ikeda M, Mitsunaga S, Shimizu S, et al. Efficacy of sorafenib in patients with hepatocellular carcinoma refractory to transcatheter arterial chemoembolization. J Gastroenterol. 2014:49(5):932-40.

36. Terashima T, Yamashita T, Arai $\mathrm{K}$, et al. Response to chemotherapy improves hepatic reserve for patients with hepatocellular carcinoma and Child-Pugh B cirrhosis. Cancer Sci. 2016;107(9):1263-9.

37. Miyaki $D$, Aikata $H$, Honda $Y$, et al. Hepatic arterial infusion chemotherapy for advanced hepatocellular carcinoma according to Child-Pugh classification. J Gastroenterol Hepatol. 2012;27(12):1850-7.

\section{Submit your manuscript to a SpringerOpen ${ }^{\circ}$ journal and benefit from:}

- Convenient online submission

- Rigorous peer review

- Open access: articles freely available online

- High visibility within the field

- Retaining the copyright to your article

Submit your next manuscript at $\boldsymbol{\nabla}$ springeropen.com 